Revista Universo Contábil, ISSN 1809-3337

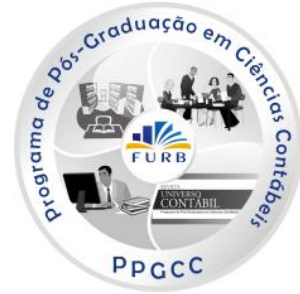

\title{
SABERES DA DOCÊNCIA QUE FUNDAMENTAM A PRÁTICA PEDAGÓGICA DO PROFESSOR QUE MINISTRA A DISCIPLINA DE GESTÃO DE CUSTOS EM UM CURSO DE CIÊNCIAS CONTÁBEIS'
}

\section{KNOWLEDGE THAT STRUCTURE THE PEDAGOGIC PRACTICE OF A PROFESSOR OF COST MANAGEMENT IN AN ACCOUNTANCY COURSE}

\section{CONOCIMIENTOS QUE ESTRUCTURAN LA PRÁCTICA PEDAGÓGICA DEL DOCENTE QUE ADMINISTRA LA DISCIPLINA DE ADMINISTRACIÓN DE COSTOS EN UN CURSO DE CIENCIAS CONTABLES}

Vilma Geni Slomski

Pós-Doutorado em Controladoria e Contabilidade pela FEA/USP Doutorado e Mestrado em Educação pela FEU/SP Professora e Pesquisadora Programa de Mestrado da Fundação Escola de Comércio Álvares Penteado FECAP Endereço: Avenida da Liberdade, 532 - Liberdade CEP 01502-001 - São Paulo - SP

E-mail: vilma.geni@fecap.br Telefone: (11) 3272-2301

Edilei Rodrigues de Lames

Mestre em Ciências Contábeis pela FECAP Coordenador e Professor da Faculdade Adventista de Hortolândia (FAH/UNASP-HT) Endereço: Rua Pastor Hugo Gegembauer, 265 - Pq Ortolândia CEP 13184-050 - Hortolândia - SP E-mail: edilei.lames@unasp.edu.br Telefone: (19) 2118-8150

Evandir Megliorini

Doutor em Ciências Contábeis pela FEA/USP Professor da Universidade Federal do ABC - UFABC Endereço: Av. dos Estados, 5001. Bairro Bangu CEP 09210-580 - Santo André - SP E-mail: evandir.megliorini@ufabc.edu.br Telefone: (11) 99766-7944

Liliane da Costa Jacobs Lames Professor e Contadora da Faculdade Adventista de Hortolândia (FAH/UNASP-HT) Mestre em Ciências Contábeis pela FECAP Rua Pastor Hugo Gegembauer, 265 - Pq Ortolândia CEP 13184-050 - Hortolândia - SP E-mail: liliane.costa@unasp.edu.br Telefone: (19) 2118-8150

\footnotetext{
${ }^{1}$ Artigo recebido em 13.03.2013. Revisado por pares em 16.09.2013. Reformulado em 10.12.2013. Recomendado para publicação em 26.12.2013 por Carlos Eduardo Facin Lavarda. Publicado em 30.12.2013. Organização responsável pelo periódico: FURB.
} 


\section{RESUMO}

A preocupação com a formação e o desenvolvimento profissional dos educadores em vista da inovação e da qualidade da educação superior aponta para a importância da implementação de política de formação dos professores universitários. Assim, esta pesquisa teve como objetivo delinear as características (tipos e natureza) dos saberes da docência que estruturam e significam a prática pedagógica de um professor que ministra a disciplina de Gestão de Custos em um curso de Ciências Contábeis, oferecido por uma IES do Estado de São Paulo, procurando evidenciar elementos que permitam melhor compreender como os professores vão construindo as competências para o desempenho da função docente ao longo de seu processo de desenvolvimento profissional. Para tanto, foi realizada uma pesquisa exploratória - qualitativa, e os dados foram coletados por meio de entrevista, com roteiro semi-estruturado. Verificou-se que os saberes docentes abrangem diferentes tipos e fontes sociais de aquisição, tais como: saber pessoal; saber dos programas; dos livros e materiais didáticos; das tecnologias e técnico-disciplinar. Esses conhecimentos são pragmáticos, ligados ao contexto de ação, à pessoa do professor e à profissão docente; são também existenciais, orientados por crenças, valores e atitudes. Assim, o modo de ser e de estar na docência tende a configurar as disposições, ou as maneiras de agir na prática pedagógica. Conclui-se, dessa forma, que o modo de ser e de estar na docência tende a configurar as disposições, ou as maneiras de agir diante do ensino. Desse modo, os saberes da docência possuem um caráter temporal e social e remetem a processos adquiridos e aperfeiçoados no âmbito da prática e da carreira docente.

Palavras - chave: Saberes da docência. Gestão de custos. Educação Contábil. Formação de professores.

\section{ABSTRACT}

The worries about the professors' learning and development processes concerning the innovations and the quality of university education highlight the importance of university professors' learning politics. In this context, the aim of this research was to investigate the features (type and nature) of the knowledge that structure the pedagogic practice of a professor of Cost Management in an Accountancy course offered by a university in São Paulo city, as a way to highlight elements that could lead to a better understanding of the way professors build the competences for performing their academic role throughout the professional development. Therefore, it was made an exploratory-qualitative research, and the data was collected by means of observation and interview, with a semi-structured script. It was verified that the professors' knowledge have different types and social sources of acquisition, like: Personal knowledge, Programme knowledge, books and material knowledge, technological and technical knowledge. These are pragmatic knowledge, strongly connected with the action context, the professors self and the professional career of professor. Moreover, are considered existential, guided by beliefs, values and attitudes. So, their way of being and being a professor usually frames the dispositions, or the ways of acting in pedagogic practice. It can be concluded that the way of being and being a professor usually frames the dispositions, or the ways of acting in pedagogic practice. In this way, the learning knowledge has a temporary and social basis, and goes back to acquired and developed processes concerning the professor career and pedagogic practice.

Keywords: Professor Knowledge. Cost Management. Accountancy Education. Professor learning. 


\section{RESUMEN}

Los estudios actuales sobre la formación docente, junto a los estudios sobre la actualidad escolar, constituyen el conjunto de temas considerados como movilizadores de la reflexión didáctica y de la práctica de la enseñanza superior. Con este enfoque, el presente estudio ha analizado los componentes y la naturaleza de los conocimientos que estructuran y significan la práctica pedagógica de un docente que administra la disciplina de Administración de Costos en un curso de Ciencias Contables ofrecido por un IES del Estado de São Paulo. Para ello, se ha llevado a cabo un estudio exploratorio cualitativo. Los datos se han recopilado por medio de entrevista con guión semiestructurado. Se ha constatado que los conocimientos docentes alcanzan diferentes tipos y fuentes sociales de adquisición, tales como: conocimiento personal; conocimiento de los programas, de los libros y materiales didácticos, de las tecnologías y conocimiento técnico disciplinario. Estos conocimientos son pragmáticos, vinculados al contexto de acción, a la figura del profesor, la labor docente, son también existenciales, orientados por creencias, valores y actitudes. De esta forma, el modo de ser y de estar en la docencia tiende a configurar las disposiciones o los modos de actuar en la práctica pedagógica. Como conclusión, el conocimiento de la docencia posee un carácter temporal y social, remite a los procesos mediante los que se han adquirido en el ámbito de la carrera docente y de la práctica profesional contable.

Palabras clave: conocimientos docentes. profesor de costos. educación contable.

\section{INTRODUÇÃO}

As mudanças sociais, culturais e tecnológicas exigem o repensar das formas tradicionais de conceber o conhecimento e revigoram discussões sobre currículo e métodos de ensino/aprendizagem, trazendo novas exigências ao debate pedagógico na Universidade. Diferentes estudos (MORAES, 1996; CUNHA, 1998; SAVIANI, 2007; MORIN, 2005; FAZENDA, 2002; SANTOS, 2006) ressaltam que o problema da educação decorre do modelo de ciência que prevalece em certo momento histórico e influencia as questões epistemológicas e as teorias de aprendizagem, das quais derivam a mediação pedagógica e suas práticas correspondentes.

Para Santos (2006), a docência universitária exige a formação pedagógica do professor para atender a essa nova demanda de ensino advinda da sociedade da informação, que tende a diversificar e complexificar ainda mais o conhecimento, tendo o docente que responder reflexivamente a essa nova tendência. Nessa linha de pensamento, Hargreaves (1996), em uma análise sobre a contemporaneidade, menciona que a sociedade do conhecimento é uma sociedade aprendente. Esse imperativo impõe mudanças na relação homem/conhecimento, tendo em vista as novas formas de conceber e de pensar a realidade. Esse fato perpassa diferentes áreas do saber e atinge os discursos e as práticas pedagógicas que constroem e constituem o cotidiano da Universidade, que se vê diante da necessidade de repensar as competências e a formação dos docentes.

Quando se questiona o desempenho do profissional formado pela universidade, é a qualidade do ensino por ela oferecido que está sendo avaliada. Esse fato remete à reflexão sobre o papel da universidade e sobre a construção de um projeto pedagógico, que a concretize não somente como instituição produtora do conhecimento científico, mas também como formadora de profissionais competentes a serviço da difusão do conhecimento e do desenvolvimento social. Alia-se a essa situação da formação do professor o fato de diversas instituições de ensino, algumas delas tradicionais, oferecerem cursos de graduação que apresentam resultados insatisfatórios em avaliações oficiais, conforme publicação do Diário Oficial da União, de 08 de janeiro de 2013, que relacionou 38 cursos de 21 instituições de ensino superior deficitários. 
Em relação aos formandos em ciências contábeis, foco deste artigo, no primeiro exame de suficiência de 2012, aplicado pelo Conselho Federal de Contabilidade, menos da metade dos bacharéis foram aprovados (VALOR ECONÔMICO, 2012). Essa situação também pode ser observada em exames da OAB e de Medicina. Do total de 114.763 candidatos que fizeram a primeira fase do exame da OAB em 2012, somente 19.134 foram aprovados, o que corresponde a um percentual de apenas 16,67\% (NASSIF, 2013).

Ao seguir essa mesma tendência, o CREMESP, referente ao curso de graduação em medicina, reprovou 54,5\% dos formandos em seu exame realizado em 2012 (Portal G1, 2012). Basta uma rápida pesquisa nos sites de busca na internet para constatar a proliferação de cursos preparatórios para esses exames, situação que reflete a baixa qualidade na formação dos estudantes. Com relação a essa questão, Nossa (1999), já alertava para o fato de que diversos cursos, de instituições com pouca tradição ou baixa concorrência no vestibular, atraem estudantes menos qualificados. Esses estudantes, em sua maioria, trabalham e estudam, esperando que o diploma seja útil para conseguir melhores salários e oportunidades no mercado de trabalho. Complementa o autor que é desses estudantes que sairá a maioria dos docentes que irão ingressar no ensino superior.

Ao contrariar essa condição de formação acadêmica nas áreas de negócios, as empresas inseridas em um ambiente globalizado e altamente competitivo necessitam, cada vez mais, de profissionais qualificados e com sólida formação acadêmica. Isso indica que a formação pedagógica do professor universitário é tema primordial quando se discute a melhoria da qualidade de ensino na graduação.

A indicação da função social da universidade e das características da função de ensinar evidencia a necessidade de formação para a docência, diferenciada daquela tradicionalmente praticada nas IES. Na discussão sobre os saberes da ação docente, Tardif, Lessard e Lahaye (1991) e Tardif e Raymond (2000) atribuem à noção de "saber" um sentido amplo; esse saber engloba um conjunto de conhecimentos teóricos e práticos necessários ao exercício da profissão, isto é, conhecimentos, habilidades (ou aptidões) e atitudes dos docentes, aquilo que por outros autores é classificado como saber, saber-fazer e saber ser professor (ZABALZA, 2004).

Por outro lado, os autores reconhecem a existência de ideias preconcebidas sobre a docência, tais como: ao professor, basta saber o conteúdo; ou ter talento; ou ter bom senso; ou seguir a intuição; ou ter experiência/prática e, às vezes, duas ou mais dessas ideias acham-se articuladas. A docência, sendo abordada como um ofício feito de saberes, relaciona-se com as perspectivas encontradas na literatura educacional, que defendem um repertório de saberes próprios da docência. Há algum tempo, a situação do ensino e da aprendizagem na universidade tornou-se preocupação dos pesquisadores e profissionais do ensino (SHULMAN, 2004; PERRENOUD, 1996; KNOWLES; COLE; PRESSWOOD, 1994). Conforme o exposto, a discussão sobre a formação de professores, especialmente os universitários, tem ocupado lugar de destaque em centros de pesquisas e nos programas de pós-graduação.

A necessidade de se questionar a qualidade do ensino superior no Brasil, e nesse âmbito, a formação docente, tem se constituído linha de pesquisa e na possibilidade de se entender a atual situação, problematizar e encontrar caminhos que apontem formas para solucionar a problemática, mesmo que a longo prazo. Para a docência universitária, assim como em qualquer outro nível de ensino, é desejável que os professores detenham, além dos conhecimentos específicos da área em que ministram a disciplina, conhecimentos pedagógicos relacionados ao ensinar e aprender, portanto, formação na área da educação. Ademais, são bem vindos os conhecimentos experienciais do professor, suas percepções do mundo do trabalho no qual os futuros profissionais estarão inseridos. Essas indicações motivaram a realização deste estudo, que buscou oferecer resposta à seguinte questão de pesquisa: Quais são as características (tipos e natureza) dos saberes da docência que estruturam e significam a prática pedagógica de 
um professor que ministra a disciplina de Gestão de Custos em um curso de Ciências Contábeis oferecido por uma IES do Estado de São Paulo?

Ao se considerar essa problemática, o objetivo desta pesquisa foi delinear as características (tipos e natureza) dos saberes da docência que estruturam e significam a prática pedagógica de um professor que ministra a disciplina de Gestão de Custos em um curso de Ciências Contábeis oferecido por uma IES do Estado de São Paulo, procurando, assim, evidenciar elementos que permitam melhor compreender como os professores vão construindo as competências para o desempenho da função docente ao longo de seu processo de desenvolvimento profissional.

\section{FUNDAMENTAÇÃO TEÓRICA}

Nos últimos anos, tem-se afirmado a importância do papel do professor como educador, atento permanentemente às necessidades de aprendizagem e desenvolvimento dos futuros profissionais. Em contrapartida, o professor não pode exercer o seu papel com competência sem uma formação adequada para ministrar as disciplinas ou saberes de que está incumbido. Nesse sentido, nessa seção, são discutidos tópices referentes às tendências e perspectivas na formação pedagógica do professor universitário, os saberes da docência, estudos e pesquisas sobre o processo de aprendizagem da docência e o ensino da disciplina de Gestão de Custos no curso de Ciências Contábeis.

\subsection{A formação pedagógica do professor universitário: tendências e perspectivas}

A instituição universitária tornou-se foco de atenção, pelo questionamento da qualidade do conhecimento nela produzido e dos processos educativos pelos quais é responsável, visando à disseminação do conhecimento científico e formação de profissionais de diferentes áreas. As demandas externas por excelência acadêmica e pertinência social da universidade têm se intensificado. Alguns reflexos se fazem sentir internamente, basicamente pelos processos de autoavaliação desencadeados, na busca de um diagnóstico sobre a real situação vivida pela academia e de alternativas para resolver as questões que se colocam sobre o seu papel. (KOURGANOFF, 1990).

A formação pedagógica do professor universitário é uma das questões centrais quando se discute a melhoria da qualidade de ensino na graduação. E a quem cabe tal tarefa? Que formação se faz necessária para os profissionais do ensino superior zelarem de forma competente pela qualidade do ensino? E como e onde se pode desenvolver essa formação?

As respostas a esses questionamentos conduz à discussão, em um primeiro momento, acerca dos cursos de pós-graduação. A formação do professor voltada ao ensino superior tem acontecido mediante programas de pós-graduação lato e stricto-sensu. No entanto, cabe ressaltar que esse modelo de formação tem como base a pesquisa e não a formação didática. Cada vez mais se ampliam as exigências de que os professores universitários obtenham titulação acadêmica de mestre e doutor. Para satisfazer a essa exigência, verifica-se o desenvolvimento de políticas de expansão dos programas de pós-graduação no Brasil. Todavia, é questionável se essa titulação, do modo como vem sendo realizada, pode contribuir efetivamente para a melhoria da qualidade da didática no ensino superior.

Tais constatações apontam preocupações e questionamentos acerca da correlação entre a crescente especialização oferecida pelos cursos de pós-graduação e a melhoria da qualidade docente dos professores universitários. Estudos apontam que os altos níveis de qualidade atingidos pelos programas de pós-graduação não têm sido suficientes para uma melhor qualificação do professor para o exercício da docência universitária (PIMENTA; ANASTASIOU, 2002; MASETTO, 2003; PIMENTEL, 1993). Cunha (2001) corrobora essa 
ideia, atribuindo, em grande medida, tais problemas à visão distorcida que se tem quanto ao exercício da docência, em que se acreditava (e alguns ainda acreditam) que quem sabe fazer automaticamente está apto para ensinar, não havendo grandes preocupações quanto ao preparo didático-pedagógico daqueles que pretendem seguir a carreira docente.

Para o exercício da docência universitária, não se tem, habitualmente, exigido elementos referentes à formação para o magistério. Essa formação, quando ocorre, limita-se ao cursar de uma disciplina da área da Metodologia do Ensino Superior durante a pós-graduação, com carga horária média de 60 horas. Constitui-se assim, para a maioria dos profissionais que atuam nas salas de aulas das universidades, a principal experiência de sistematização de conhecimentos, atitudes e habilidades.

A assimetria entre a realidade das funções atribuídas aos docentes universitários e a realidade dos saberes trabalhados na formação para o ensino é uma questão que dificulta e limita a formação profissional; se não forem buscadas soluções e melhorias, poderá se agravar ainda mais a crise da qualidade da educação universitária no Brasil. Para Zabalza (2004, p. 78), alguns eixos importantes na construção da identidade docente devem ser considerados, tais como "a percepção do seu papel e a hierarquia nos propósitos; os centros de interesse pessoal; a satisfação que o trabalho proporciona; a carga de trabalho que implica a docência, a saúde, o stress e a autonomia".

Diante de tal contexto, o mais importante, além de pensar em política de formação, é conhecer quais são os saberes ou as competências imprescindíveis para que o profissional docente possa atuar na universidade, em prol do perfil do profissional que se deseja e a universidade se incumbe de formar. De uma forma simplificada, diz-se que o professor é alguém que deve desenvolver competência para ensinar, envolvendo questões como: Quem ensinar? O que ensinar? Por que e para que ensinar? Como ensinar? Como avaliar? (ZABALZA, 2004).

Todas essas questões de reflexão sobre a prática pedagógica fundem-se em um ponto de mudança da postura e visão do papel da educação. A questão central refere-se ao fato de o professor considerar o modo como o aluno aprende para elaborar situações de aprendizagem significativas, em que os profissionais da educação se transformem em profissionais da "aprendizagem". Em vez de especialistas que apenas conhecem bem o assunto, docentes que conhecem bem o aluno e suas raias necessidades de aprendizagem Para além do "o quê" e do "como", é necessário saber "para quê" e "por quê" se ensina. Assim, os métodos e instrumentos mais adequados para o acesso ao conhecimento por meio da reflexão e da crítica serão utilizados como uma forma de tornarem os alunos autônomos e produtores do seu próprio conhecimento, não apenas reprodutores; tudo isso acentuado tanto pela atividade do aluno quanto do professor. (ZABALZA, 2004; PIMENTA; ANASTASIOU, 2002).

Enfim, diante dessas reflexões a respeito da formação docente, destacam-se alguns compromissos primordiais que o professor deve assumir perante a docência: a) compromisso com a sua pessoa, concretizado pela formação continuada; b) compromisso com a profissão, revelado pela aquisição de conhecimentos didático-pedagógicos e da melhoria do ensino; c) compromisso com os alunos, demonstrado quando se propicia a aprendizagem, considerando as diferenças em sala de aula; d) compromisso com a instituição em que se trabalha, dando origem a outro compromisso: com a construção do projeto pedagógico do curso e com o trabalho coletivo (PIMENTA; ANASTASIOU, 2002).

Nesse sentido, autores como Vasconcelos (1998), Masetto (2003), Pimenta e Anastasiou (2002) defendem as seguintes dimensões para a qualidade da prática de ensino:

1) a dimensão técnico-científica, isto é, o domínio de seu campo específico de atuação. Aqui, é importante o domínio dos conteúdos conceituais e da pesquisa, pois essa ancoragem é necessária para as demais dimensões da qualidade do profissional; 
2) a dimensão humana, que enfatiza as relações interpessoais presentes na tarefa educativa, a presença da sensibilidade e da afetividade;

3) a dimensão prática, que supõe que o docente tenha conhecimento da prática profissional, para proporcionar ao aluno uma visão real e mais atualizada, a fim de dar um significado ao conteúdo que está sendo ensinado para a efetivação da aprendizagem;

4) a dimensão ética, que se relaciona à orientação da ação, baseada no princípio do respeito e da solidariedade, do convívio e da realização de um bem coletivo;

5) a dimensão pedagógica do docente, que vai além de ministrar aulas, contemplando todo o planejamento do ensino, o que inclui desde os objetivos gerais da disciplina, o conhecimento dos alunos, do mercado, do processo de ensino e aprendizagem, da avaliação da aprendizagem, das possibilidades de construção e reconstrução do conhecimento, até a relação professor-aluno;

6) a dimensão político-social, que diz respeito à participação na construção coletiva da sociedade e ao exercício dos direitos e deveres;

7) a dimensão didática, que envolve o domínio dos fundamentos do processo de ensino aprendizagem, seus objetivos, suas metodologias, suas formas de avaliação e o domínio da tecnologia aplicada à prática da sala de aula.

Essas exigências não são apenas operacionais, mas, acima de tudo, de concepção de mundo e educação como totalidade, uma visão crítica da educação, da necessidade de mudança de cultura e do modo de pensar e agir na educação superior.

\subsection{Os saberes docentes}

A década de 1980 marcou a intensificação do movimento de profissionalização do ensino e, com isso, um apelo para a constituição de um repertório de conhecimentos docentes. O esgotamento do modelo da racionalidade técnica e das abordagens psicologizantes que concentravam a atenção nos processos de aprendizagem despertou renovado interesse pela busca da compreensão dos processos envolvidos no ensino, considerando a especificidade da cultura escolar e dos saberes dos professores enquanto profissionais dotados de subjetividades e intencionalidades (MIZUKAMI, 1986, SCHÖN, 1987; SHULMAN, 2004; TARDIF; LESSARD; LAHAYE, 1991; NÓVOA, 1992; SACRISTÁN, 1995; TARDIF, 1999; PERRENOUD, 1999; PIMENTA, 1999). Tais estudos, ao abordarem a questão do conhecimento, ou do saber dos professores, costumam identificá-lo como sendo composto por dimensões que intervêm diretamente na prática pedagógica. Trata-se de um conhecimento essencialmente orientado para a ação e que se desdobra em domínios interligados. Nesse contexto, o conceito do saber docente tem sido utilizado como ferramenta teórica para dar conta dessa problemática.

O sucesso profissional na tarefa de ensinar exige do professor o domínio e a articulação dos vários elementos que compõem o seu trabalho, ou seja, "uma base de conhecimentos", que é "um conjunto de compreensões, de conhecimentos, habilidades e disposições necessárias para a atuação efetiva em situações específicas de ensino e aprendizagem”. (MIZUKAMI, 1986, p. 66).

Em conformidade com o foco desta pesquisa, foram eleitos para uma interlocução os estudos de Tardif e seu grupo de pesquisa (1991, 1999, 2000). Justifica-se a escolha pelo fato de encontrar nas reflexões desses autores a possibilidade de melhor conhecimento e compreensão dos saberes do docente em estudo, caracterizando, assim, os componentes e a natureza dos diferentes saberes necessários ao exercício do magistério superior. Nesses trabalhos, os autores discutem os fundamentos epistemológicos da prática profissional docente. O eixo de suas discussões centra-se na premissa de que a competência docente integra uma pluralidade de saberes, tais como: 
a) Os Saberes Disciplinares ou Específicos, que correspondem aos saberes situados nos diversos campos de conhecimento (matemática, história etc.), emergentes da tradição cultural e dos grupos sociais produtores de saberes;

b) Saberes Profissionais para o Magistério, que se referem ao conjunto de saberes contemplados pelas instituições de formação de professores;

c) Saberes Curriculares, que são os saberes relativos à área da didática. Compreendem os discursos, objetivos, conteúdos e métodos contemplados pela didática para a operacionalização dos saberes disciplinares;

d) Saberes da Experiência, que se referem aos julgamentos privados responsáveis pela elaboração, ao longo do tempo, de uma jurisprudência de truques, capazes de contribuir para o ensino.

Tais saberes, ao serem validados, incorporam-se à prática profissional sob a forma de "habitus", termo proposto por Bourdieu (1983) para designar o conjunto de habilidades, hábitos, saber-fazer e saber-ser que vão configurando o "metiér" docente. Para Tardif, Lessard e Lahaye (1991, p. 221), o saber-fazer do professor deve expressar todos esses domínios de saberes: "O (a) professor (a) padrão é alguém que deve conhecer sua matéria, sua disciplina e o seu programa, que deve possuir certos conhecimentos das ciências da educação e da pedagogia, sem deixar de desenvolver um saber prático fundado em sua experiência cotidiana com os alunos".

Com a intenção de melhor compreender a profissão docente, Tardif e Raymond (2000) ampliaram, em suas pesquisas, o estudo dos saberes dos professores. Os autores caracterizam os saberes que servem de base para o ensino como um saber plural, ao afirmarem que: "[...] não se limitam a conteúdos bem circunscritos que dependeriam de um conhecimento especializado. Eles abrangem uma diversidade de objetos, de questões, de problemas que estão todos relacionados com seu trabalho. [...]."

Nesse sentido, dizem os autores que:

Os saberes profissionais dos professores parecem ser, portanto, plurais, compósitos, heterogêneos, pois trazem à tona, no próprio exercício do trabalho, conhecimentos e manifestações do saber-fazer e do saber-ser bastante diversificados, provenientes de fontes variadas, as quais podemos supor que sejam também de natureza diferente.

Essa definição do conhecimento indica que as aprendizagens docentes são provenientes de diversas fontes e momentos da vida do professor, tendo seu início antes do ingresso nos cursos de formação, continuando por toda sua prática de ensino. Além de plurais, Tardif e Raymond (2000) destacam que os saberes docentes são também temporais, ou seja, adquiridos por meio de processos de aprendizagens e de socialização que atravessam tanto a história de vida quanto a carreira do professor. Nesse sentido, muitos dos saberes produzidos fora do ofício de ensinar são provenientes de lugares sociais anteriores à carreira docente propriamente dita, ou fora do trabalho cotidiano.

Embora se tenha explanado sobre a classificação dos saberes por Tardif, Lessard e Lahaye (1991) e Tardif (1999) de forma linear, Tardif e Raymond (2000, p. 45), na reflexão que fazem sobre a organização dos saberes docentes, chamam a atenção para a importância de se fazer uma leitura abrangente dessas categorias, pois entendem que "os saberes não são imóveis e estáticos, nem foram produzidos no mesmo tempo, território e circunstâncias.

$\mathrm{Na}$ área contábil, vários estudos foram realizados sobre a formação de professores universitários, com destaque para alguns estudos sobre saberes docentes (LAFFIN, 2001; SLOMSKI, 2007, 2008a-b; SLOMSKI; SLOMSKI, 2008; SLOMSKI et al., 2009; SANTANA, 2009; ARAÚJO; SANTANA; CARNEIRO, 2009), cujo foco é o saber da experiência oriunda da prática, que não envolve necessariamente a educação formal para o ensino, mas que o professor utiliza em seu ensino, adquirido no decorrer de sua prática. Essas investigações sobre o conhecimento prático do professor têm oferecido contribuições não só para a valorização das competências e saberes que o professor vai construindo em sala de aula, mas também o 
reconhecimento de que a sobrevalorização do conhecimento técnico científico em relação ao conhecimento prático do professor pode impedir que as políticas de formação de professores sejam efetivas e as mudanças na prática de ensino e na qualidade da educação universitária ocorram.

\subsection{Pesquisas sobre os saberes docentes}

Dentre as pesquisas estrangeiras e nacionais apresentamos aquelas que mais têm se destacado na busca por caminhos alternativos para conhecer os saberes dos professores. Uma das primeiras pesquisas nesse sentido foi realizada pela investigadora canadense Elbaz (1983) que, a partir de uma abordagem interpretativa, propôs-se a descrever que tipo de conhecimento os professores adquirem e desenvolvem. Conforme a autora, o conhecimento do professor tem um caráter fundamentalmente prático. É um conhecimento que se forma para e ao exercer a prática pedagógica, que vai lhe dando corpo. O próprio conhecimento da disciplina, adquirido de forma teórica, é desenvolvido e refinado durante as experiências de ensino. A autora diferencia diversos domínios de conhecimento do professor, dentre os quais destaca: (a) conhecimento do conteúdo, que engloba o conhecimento da disciplina e das áreas que estudam o desenvolvimento, a aprendizagem dos alunos e as teorias sociais e (b) conhecimento experiencial, orientado pelo conhecimento do conteúdo. É a conjugação dessas duas vertentes do conhecimento com os seus valores, crenças e teorias pessoais - que a autora chama de conhecimento prático do professor - que determina a forma como esse atua nas diferentes situações em sala de aula. Ademais, considera duas possíveis origens do conhecimento prático do professor: a teoria e a experiência. Não negando o papel da primeira, ela valoriza a prática no desenvolvimento do saber.

Na década de 1990, no Brasil, vários estudos foram realizados com essa ênfase, dentre os quais se destaca a pesquisa de Caldeira (1995), cuja preocupação foi investigar os saberes implícitos construídos e apropriados pelo professor em sua prática durante sua trajetória profissional e pessoal. Ao partir dessa suposição (de que o docente se apropria e produz saberes na atividade escolar), a autora procura descrever e analisar a prática docente de uma professora do ensino fundamental e a reconstrução do processo de constituição do seu saber. Ressalta-se a importância de considerar o estudo da prática docente como processo informal, dinâmico, complexo e carregado de valores.

O estudo desenvolvido por Borges (1995) procura analisar a construção do saber docente de professores de Educação Física. Focaliza especificamente a trajetória profissional de dois professores de Educação Física a partir da análise de sua formação e prática pedagógica. Identifica que tanto as experiências vivenciadas no processo de escolarização quanto as experiências esportivas, acadêmicas e profissionais contribuem na gênese dos saberes que eles mobilizam no cotidiano da prática escolar. Dessa forma, analisando a divisão existente entre quem produz e quem transmite os conhecimentos, propõe que:

Talvez se possa pensar que a valorização dos saberes da experiência, dos saberes docentes de um modo geral, seja uma alternativa no sentido de buscar uma maior aproximação da formação acadêmica com a realidade escolar, estreitando os vínculos na relação entre teoria e prática (BORGES, 1995, p. 14).

Guarnieri (1997) investigou a atuação de professores iniciantes, partindo da ideia de que a profissão vai sendo construída à medida que o professor articula o conhecimento teóricoacadêmico, a cultura escolar e a reflexão sobre a prática docente. Ao revisar as novas perspectivas de pesquisa que analisam a questão da competência para ensinar, enfatiza que "esses novos paradigmas investigativos buscam, a partir do pensamento e desenvolvimento profissional dos professores, 'uma epistemologia da prática' que explique como se configura o processo de aprender a ensinar, de tornar-se professor" (GUARNIERI, 1997, p. 2). 
Outra pesquisadora que tem se dedicado aos estudos dos saberes dos docentes é Pimenta, que em 1999, desenvolveu suas primeiras investigações. Dentre essas, merece destaque a pesquisa desenvolvida com alunos de licenciatura. A autora enfatiza a importância da mobilização dos saberes da experiência para a construção da identidade profissional do professor. Nesse sentido, identifica três tipos de saberes da docência: a) da experiência, que seria aquele aprendido pelo professor desde quando aluno, com os professores significativos, assim como o que é produzido na prática, em um processo de reflexão e troca com os colegas; b) do conhecimento, que abrange a revisão da função da escola na transmissão dos conhecimentos e as suas especialidades em um contexto contemporâneo e c) dos saberes pedagógicos, que abrangem a questão do conhecimento juntamente com o saber da experiência e dos conteúdos específicos e que serão construídos a partir das necessidades pedagógicas reais.

A partir dos estudos apresentados, percebe-se que há diferentes tipologias e formas de se abordar a questão dos saberes docentes. Na investigação sobre esses saberes, cabe considerar não só o desenvolvimento profissional, mas também o desenvolvimento pessoal do professor, enfatizando que o saber é constituído a partir do contexto histórico e social vivenciado e esse é transformado em saber da experiência. Ao se integrar a perspectiva da busca pela revelação da epistemologia subjacente à prática docente, encontram-se os conceitos de professor reflexivo, professor - pesquisador, reflexão na ação, reflexão sobre a ação e reflexão sobre a reflexão na ação. São várias as investigações sobre as concepções, as ideias do professor, ou seja, seus conhecimentos ou seus saberes. A seguir, destacamos alguns desses estudos.

$\mathrm{Na}$ área contábil, Nossa (1999) evidencia a preocupação com a formação deficiente dos professores, apregoando políticas de educação continuada nesse campo. Em sua pesquisa, identifica as principais causas do desempenho deficiente de grande parte dos professores da área contábil, apresentando propostas de melhoria da qualidade da prática de ensino e da educação contábil. Apesar de não mencionar diretamente os saberes docentes, seu discurso evidencia a necessidade de os professores possuírem determinados saberes, ultrapassarem os limites do conhecimento específico, refletindo sobre suas ações enquanto educadores.

Nessa mesma linha de pensamento, Laffin (2001) destaca os componentes dos saberes como sendo tácitos, específicos da disciplina, e um saber pedagógico que permita ao professor efetuar a transposição didática, ampliando a possibilidade de aprendizado do aluno. Em seu ensaio teórico, defende a formação continuada dos professores como um espaço que leve a reflexões sobre seu fazer docente, transformadas em intervenções que permitam a reelaboração da sua prática docente. É somente pela busca dos saberes necessários à prática educativa que o professor se tornará autônomo e conseguirá transformar os conhecimentos curriculares em conhecimento de ensino.

Estudos sobre a formação pedagógica do ponto de vista do saber docente na área contábil começam a aparecer a partir das pesquisas de Slomski (2007, 2008a-b) e Araújo, Santana e Carneiro (2009), intensificando o debate sobre a formação de professores universitários e compondo quadros teórico-práticos para o estudo das práticas docentes. Slomski (2007) analisa as novas tendências investigativas sobre a formação de professores que valorizam os saberes docentes e defende a docência como profissão. No ensaio teórico de Slomski (2008a), encontram-se discussões sobre os saberes necessários à docência reflexiva na área contábil, com destaque para as principais competências ao ensino, tais como: as atitudinais, de ação, metodológicas e de comunicação. A autora conclui que o modelo reflexivo é fundamental na formação de professores, especialmente na área contábil, pois visa ao desenvolvimento de atitudes e competências problematizadoras das práticas de ensino e o alcance da autonomia e do pensamento crítico-reflexivo dos alunos.

Em decorrência desse estudo, Slomski (2008b) desenvolveu nova pesquisa, dessa vez com professores-pesquisadores da área Contábil, por meio do modelo tipológico de Tardif e Raymond (2000), que identifica e classifica os saberes dos professores, em vez de propor 
critérios internos que permitem discriminar e compartimentar os saberes em categorias disciplinares ou cognitivas diferentes. A autora conclui que, em vista das limitações no que se refere à formação para a docência, é a própria experiência na profissão contábil, na sala de aula, na universidade e a experiência dos pares que vem estruturando e dando sentido à prática pedagógica desses professores.

O estudo de Araújo, Santana e Carneiro (2009) apresenta críticas ao ensino da contabilidade e os saberes necessários à docência defendidos por Freire (1996), ressaltando que é preciso buscar modelos mais interativos de educação compatíveis com a Pedagogia da Autonomia, necessários para motivar os alunos à participação e aprendizagem ativa, uma das características da educação problematizadora. Esse tipo de educação "certamente irá contribuir para a formação desejada ao educando de Ciências Contábeis que ingressará no mundo do trabalho [...].” (ARAÚJO; SANTANA; CARNEIRO, 2009, p. 15).

Outra pesquisa na área contábil relevante para a discussão sobre a temática dos saberes foi a de Santana (2009), em que traça o perfil de professores universitários pelo conceito de saber docente proposto por Freire (1996). Conclui que os professores investigados caracterizam-se pela dedicação ao exercício da docência, pelo seu estilo próprio de ensino, pelo modo de conduzir as aulas, avaliar os alunos e pela defesa dos direitos dos alunos a uma aprendizagem efetiva.

O presente estudo está em conformidade com as pesquisas sobre o saber docente na área contábil, tais como (LAFFIN, 2001; SLOMSKI, 2007, 2008a-b; SLOMSKI; SLOMSKI, 2008; SLOMSKI et al., 2009; SANTANA, 2009; ARAÚJO; SANTANA; CARNEIRO, 2009), e seu foco foi no saber da experiência oriunda da prática, que não envolve necessariamente a educação formal para o ensino, mas que o professor utiliza em seu ensino, adquirido no decorrer de sua prática.

\subsection{Ensino da disciplina de Gestão de Custos no curso de Ciências Contábeis}

Esta pesquisa está voltada ao estudo da prática pedagógica do professor que ministra a disciplina de Gestão de Custos no contexto universitário. Essa disciplina integra o conteúdo de formação profissional do curso de Graduação em Ciências Contábeis (Resolução CNE/CES 10, de 16 de Dezembro de 2004).

\subsubsection{Por que Gestão de Custos?}

A geração de informações a respeito de custos das atividades empresariais sempre acompanhou as necessidades da gestão de negócios (GUERREIRO, 2006). Essa afirmação pode ser avaliada em diferentes contextos históricos. Conforme Hansen e Mowen (2003), até 1925, os gestores se preocupavam com o custeio gerencial dos produtos, rastreando a rentabilidade da empresa para produtos individuais e usando essas informações para tomadas de decisões estratégicas. No entanto, dizem os autores, até 1925, a maior parte dessa ênfase foi abandonada em favor do custeio para estoque, de modo a atender a necessidade de relatar custos a usuários externos. Os autores destacam que, aparentemente, os gestores não necessitavam de informações detalhadas sobre custos de produtos individuais enquanto as empresas fabricavam produtos homogêneos, consumindo recursos na mesma proporção. De 1950 a 1960, foram desenvolvidos esforços para melhorar a utilidade gerencial dos sistemas de custos.

As recessões econômicas de 1980 e 1990, juntamente com o aumento da competitividade em nível mundial, passaram a exigir o custeio mais preciso dos produtos e aumento do controle de custos para tomada de decisões (HANSEN E MOWEN, 2003). Para atender às novas demandas proporcionadas por esse ambiente competitivo, novas ferramentas relacionadas a custos foram desenvolvidas e incorporadas aos sistemas de custeio. Entre elas, o Custeio Baseado em Atividades (Custeio ABC), Target Costing, custeio do ciclo de vida, custeio kaizen e a gestão econômica. 
Assim, a informação de custos toma nova dimensão, passando a ser uma informação estratégica que precisa ser gerenciada. Sobre isso, Blocher et al (2007) consideram que "Em virtude dos fatores estratégicos estarem crescendo em importância para a gestão, a gestão de custos transformou seu papel tradicional de custo do produto e controle operacional em um foco mais amplo e estratégico." Concluem que "A gestão estratégica de custos é o desenvolvimento de informação de gestão de custos com o objetivo de facilitar a principal função de gestão, a gestão estratégica."

Essa mudança de posicionamento para a gestão de custos parece ser uma forma de diferenciar e evidenciar a percepção de que tem havido preocupação da contabilidade em manter-se atual e imprescindível aos processos de tomada de decisão. Assim, não se pode mais ministrar o mesmo conteúdo de Gestão de Custos de 10, 15 ou mais anos atrás. Para que o contador se prepare para o mundo dos negócios, a academia e a realidade das empresas precisam andar em consonância.

\section{METODOLOGIA DA PESQUISA}

Ao se considerar o objetivo de investigar os saberes que fundamentam a prática pedagógica do professor que ministra a disciplina Gestão de Custos, entendeu-se que a pesquisa exploratória, segundo Moreira e Caleffe (2009) e a abordagem qualitativa, como relata Minayo (2008), seria a melhor opção metodológica a adotar.

O estudo delimitou-se a um curso de ciências contábeis oferecido por uma IES localizada na região metropolitana de Campinas, no estado de São Paulo. A escolha deu-se em função de a IES oferecer o curso de bacharelado em Ciências Contábeis e de ser aquela que o professor participante da pesquisa leciona.

Nesse curso há 20 professores e, dentre eles, foi identificado o professor que ministra a disciplina de custos há mais tempo na IES. Outros critérios para a escolha foram: a) ser professor efetivo na disciplina e no curso; b) estar em sala de aula no semestre em que foi realizada a pesquisa; c) ter experiência no ensino da disciplina em questão.

Esses procedimentos são pré-requisitos nas pesquisas qualitativas, em que a escolha dos sujeitos é intencional e focada naquele que possui a representatividade e resposta possível ao problema investigado (MICHELAT, 1982). MINAYO (2008) corrobora essa ideia quando diz que, na pesquisa qualitativa, não prevalece leis, generalizações, relações entre variáveis, comprovação de hipóteses, testagem e índices. Por isso, o professor sujeito desta pesquisa foi escolhido pela sua representatividade diante da sua experiência de ensino da disciplina de custos no contexto universitário e de seus saberes construídos na trajetória da docência.

Os dados da pesquisa foram coletados por meio de entrevista, sendo essa uma forma de se obter informações sobre determinado assunto, pela conversa de natureza profissional com outra pessoa (MARCONI E LAKATOS, 2008), além de permitir averiguação de fatos, opiniões, sentimentos, planos de ação e conduta do pesquisado. (SELLTIZ, 1965). A entrevista foi realizada na sala dos professores da própria IES.

\section{RESULTADOS E DISCUSSÕES}

Os dados foram categorizados segundo o roteiro de entrevista (perfil demográfico, formação acadêmica, conhecimentos específicos da área - disciplina, conhecimentos didáticos e pedagógicos - saberes docentes) e o modelo teórico proposto por Tardif e Raymond (2000), que prevê questões que abarcam aspectos da formação e do desenvolvimento profissional do professor, cobrindo aspectos relacionados aos (1) saberes pessoais; (2) saberes provenientes da formação escolar; (3) saberes provenientes da formação profissional para o magistério; (3) saberes provenientes dos programas, materiais e livros didáticos e (5) saberes provenientes da experiência na profissão. 
A análise de conteúdo teve como foco central a emergência do tema. Para Minayo (2008, p. 86), "O tema é a unidade de significação que se liberta naturalmente de um texto analisado segundo critérios relativos à teoria que serve de guia à leitura e organização dos dados".

\subsection{Quem é o professor colaborador?}

O professor é graduado em Ciências Contábeis, com MBA em gestão empresarial e mestrando em pós-graduação em Ciências Contábeis. Possui experiência profissional na área de custos, em que trabalhou por mais de 20 anos, em cargos de gerência contábil e controladoria em empresas do ramo industrial e financeiro. Tem 42 anos de idade.

Há cinco anos, iniciou sua trajetória como professor e, em paralelo à docência, exerceu cargo administrativo no setor financeiro. Atualmente, mantém-se na área acadêmica, com dedicação integral, e ter uma empresa de consultoria contábil.

O conteúdo de custos é ministrado nas disciplinas: Contabilidade de Custos, Contabilidade Gerencial e Análise de Custos, oferecidas nessa mesma ordem a partir do terceiro semestre. Alinhado com os autores pesquisados, o professor não frequentou cursos sobre didática do ensino superior. A esse respeito, diz que "aprendeu a ensinar ensinando", ou seja, pela experiência, reforçada pela vivência na profissão, com apoio dos livros didáticos e com seus próprios alunos. Esse dado corrobora o raciocínio de Tardif e Raymond (2000), Masetto (2003) e Pimenta e Anastasiou (2002), ao afirmarem que, comumente, os professores são selecionados para o magistério superior levando-se em consideração a sua especialização no assunto, e muitas vezes, é preconcebida a ideia de que basta saber fazer para saber ensinar.

\subsection{Perfil profissional dos formandos}

A Resolução CNE/CES 10, de 16 de dezembro de 2004, instituiu as Diretrizes Curriculares Nacionais para o Curso de Graduação em Ciências Contábeis. Assim, cabe às IES adequarem seus projetos pedagógicos ao que preceitua essas diretrizes. As IES têm a função de formar profissionais capazes de inserção social e profissional e contribuir para o desenvolvimento social (LDB, 1996). Os conhecimentos que visam a essa formação são selecionados e socializados por meio do currículo do curso e materializados em cada disciplina. Nessa linha são apresentados os resultados desta pesquisa. Neste ponto, descreve-se a formação do aluno pela ótica do professor, por meio da análise da seguinte proposição: O professor revela o conhecimento dos grandes princípios educacionais e do sistema de ensino, seu valor e sua utilidade.

$\mathrm{Na}$ entrevista, o professor foi questionado sobre a importância de sua disciplina no currículo do curso, passando a tecer comentários com base no projeto pedagógico, nos programas de ensino, nos livros didáticos, recursos e outros materiais que utiliza. O entrevistado revela conhecimentos dos grandes princípios educacionais e do sistema de ensino, discorrendo sobre a proposta pedagógica do curso, seu valor e sua utilidade. Mostra ter ciência do papel desse conhecimento na formação do aluno; no entanto, sua visão ainda é isolada das demais áreas do conhecimento, é um olhar ainda técnico sobre o ensino, ligado apenas ao exercício da profissão, conforme se observa em sua fala:

É a primazia da contabilidade, com ela se consegue mensurar a realidade de uma empresa. A gestão de custos é de suma importância para a formação do aluno, por meio do conhecimento adquirido, o aluno estrutura a informação, com ela é que ele vai conseguir fornecer relatórios para a tomada de decisão (DADOS DA ENTREVISTA).

Esse dado remete à necessidade de se estabelecer a organização curricular pela construção coletiva do Projeto Político Pedagógico e do currículo interdisciplinar, a fim de se alcançar o perfil profissional esperado para o formando, em termos de competências e habilidades próprias que estejam alinhadas ao atual cenário econômico, em que a formação dos profissionais possa responder aos desafios que o mundo lhes coloca (LDB, 1996). 
A noção ainda fragmentada da disciplina é reforçada pela proposta disciplinar do currículo e pela ausência de oportunidade para interagir com as outras disciplinas e demais professores. Esse fato pode ser visto quando o professor diz que:

A Instituição elabora a matriz curricular na qual o conteúdo da disciplina é transmitido de forma gradativa. Acredito que é uma forma mais adequada tanto para o professor coordenar o que vai lecionar como também para o aluno assimilar o conteúdo que lhe é transmitido. [...] Transmitindo gradativamente o conteúdo facilita o aprendizado (DADOS DA ENTREVISTA).

Conforme Tardif, Lessard e Lahaye (1991, p. 8), os professores comumente não são considerados gestores do conhecimento curricular. Seu conhecimento sobre o ensino é proveniente dos programas e livros didáticos usados no trabalho, uma vez que mantêm uma relação exterior a esse saber, sua aproximação acontece mais no nível de execução e menos no de gestão. Os autores afirmam que o professor:

mantém uma 'relação de exterioridade', ou alienação, porque já os recebem determinados em seu conteúdo e forma [...]. Portanto esses conhecimentos não lhes pertencem, nem são definidos ou selecionados por eles. [...]. Não obstante, com os saberes da experiência o professorado mantém uma "relação de interioridade". E por meio dos saberes da experiência, os docentes se apropriam dos saberes das disciplinas, dos saberes curriculares e profissionais (TARDIF, LESSARD E LAHAYE (1991, p. 8).

Esse fato pode ser observado quando o entrevistado deixa clara sua relação com a totalidade do saber que compõe o currículo:

A IES disponibiliza o projeto pedagógico do curso para o professor. Cabe ao professor extrair dele os elementos orientadores da formação profissional pretendida (DADOS DA ENTREVISTA).

Outra categoria de saber didático pode ser constatada quando o professor relata experiências coletivas, troca de experiências entre os professores e o uso de recursos e estratégias de ensino. Esse saber pode ser classificado como um saber dos programas, materiais e livros didáticos. $\mathrm{O}$ professor diz que:

Temos um projeto que se chama projeto integrador. Nós o desenvolvemos da seguinte forma: ministrado o conteúdo, o aluno vai até uma empresa e verifica sua aplicação. Assim, no primeiro semestre em que a disciplina Gestão de Custos é ministrada, o aluno observa o processo da linha de produção, identificando a ocorrência dos custos. As observações efetuadas embasam a apresentação de um seminário. Os alunos podem ser contemplados com bolsas de estudo PIBIC, cabendo aos professores orientar e coordenar (DADOS DA ENTREVISTA).

Essas falas mostram um saber ligado à experiência dos pares, à reflexão e à prática. Essa fonte social refere-se ao exercício da docência na universidade na sala de aula, denominado saber da experiência (PIMENTA; ANASTASIOU, 2002).

\subsection{Explorando o conhecimento didático e pedagógico: o que e como ensinar?}

O conhecimento didático do professor é resultado de um processo de aquisição que ocorre ao longo da vida, expresso no seu modo de pensar, escrever, verbalizar e fazer. Esse conhecimento se revela por meio de um discurso sobre uma prática ou um modo de agir. Para Pimenta e Anastasiou (2002), a docência no ensino superior está ligada a experiências no ensino, isto é, o professor "aprendeu a ensinar ensinando", reforçadas pela vivência na profissão com apoio dos livros didáticos e seus próprios alunos. As seguintes proposições serviram de guia:

\section{a. Conhecimento da matéria, do planejamento das aulas e sua organização}

O professor entrevistado foi convidado a escolher um tema da ementa para relatar como pensa e ministra sua disciplina. O tema escolhido foi "Métodos de Custeio". Em primeiro lugar, esclareceu qual seria seu objetivo com esse conteúdo: o aluno deveria compreender os métodos 
de custeio e sua aplicação prática, demonstrando assim um conhecimento técnico, conforme sua fala:

Em linhas gerais, são discutidos dois métodos de custeio: absorção e variável. [...] $O$ objetivo é que o aluno conheça bem os dois métodos, pois são os mais utilizados pelas empresas (DADOS DA ENTREVISTA).

Percebe-se a importância que o professor atribui à aplicação prática do conhecimento. Para Tardif e Raymond (2000), esse saber é pragmático; está intimamente ligado ao contexto de ação, à pessoa do professor e ao seu modo de exercer a docência. Isso pode ser verificado quando o professor explica a sequência e o modo como trabalha o conteúdo:

Primeiro faço uma introdução, onde abordo conceitualmente os métodos de custeio. Resgato os antecedentes históricos. Na sequencia trabalho a parte prática, apresentando um exemplo e propondo exercícios. Depois, apresento um "case", no qual os alunos identificam os custos incorridos, por exemplo, na fabricação de uma turbina (DADOS DA ENTREVISTA).

O professor menciona conceitos e fatos que acredita serem importantes na disciplina e que os alunos apresentam dificuldade maior em aprender:

$O$ aluno tem dificuldade de entender determinados conceitos que são vitais para a disciplina. Por exemplo, o que é um gasto e como ele se classifica em custo, despesa ou investimento. Quando o custo é fixo ou variável, direto ou indireto. O entendimento dos métodos de custeio fica facilitado quando os conceitos são assimilados (DADOS DA ENTREVISTA).

Esses dados mostram que os saberes dos professores abrangem uma diversidade de objetos, questões e problemas que estão todos relacionados com seu trabalho. Como apontam Tardif e Raymond (2000), essa é uma das manifestações possíveis do saber-fazer e do saberser professor, "bastante diversificado, proveniente de fontes variadas e provavelmente também de natureza diferente".

\section{b. Conhecimento das experiências de vida dos alunos: empatia e criatividade no ensino}

O professor-colaborador revela um modo de pensar e agir no ensino que é orientado por crenças, valores e saber disciplinar. Na fala a seguir, revela habilidades e atitudes que têm na experiência da profissão a fonte primeira de sua competência e seu saber ensinar:

O que vai impactar muito no aprendizado do aluno é a forma como é transmitido o conteúdo. Considero que o professor deve ter aquele feeling de perceber quando o aluno aprendeu ou não. [...]. Eu busco responder todas as perguntas [...], busco diversificar os exemplos apresentados durante as aulas. Considero ineficaz discutir o mesmo assunto durante todo o tempo de aula sem apresentar um caso prático (DADOS DA ENTREVISTA).

Nesse caso, os saberes são também existenciais. As falas anteriormente expostas estão de acordo com os estudos de Tardif e Raymond (2000), quando dizem que o pensamento do professor envolve sua própria história de vida, intelectual, afetiva, pessoal e interpessoal. Podese dizer então que é a partir dessa compreensão do conhecimento específico da matéria que os professores adquirem conhecimento sobre como ensiná-la. Esse dado corrobora o estudo de Elbaz (1983), quando afirma que o conhecimento do professor tem um caráter fundamentalmente prático, mas orientado pelo conhecimento do conteúdo da disciplina. Nesse sentido, a autora destaca que esse conhecimento se forma para exercer a prática pedagógica, a qual vai sendo orientada tanto por um conhecimento específico quanto por crenças, valores e atitudes diante da disciplina.

Desse modo, pode-se inferir que o professor, ao investigar, aprende com os programas, os livros e outros recursos curriculares. Esse conhecimento tem um caráter fundamentalmente técnico, orientado pelo conhecimento do conteúdo, crenças, valores e atitudes diante da disciplina. Desse modo, o conhecimento se forma para exercer a prática pedagógica e vai sendo alimentado por ela. Pode-se dizer também que é a partir dessa compreensão da matéria que os professores adquirem conhecimento sobre como ensiná-la, como os alunos a aprendem, como 
os materiais curriculares são organizados na disciplina e como tópicos particulares são mais bem incluídos no currículo.

\section{CONCLUSÕES E NOVAS QUESTÕES}

Foi possível constatar com a pesquisa, que esses saberes do professor são compostos por conhecimentos de naturezas diversas, abrangendo diferentes tipos e fontes sociais:

a) Saber pessoal, proveniente de sua história de vida e socialização primária, revelado quando o professor demonstra valorizar as experiências de vida dos alunos, desenvolvendo a empatia e a afetividade no ensino e quando busca o dinamismo em suas aulas. Esses saberes são orientados por crenças, valores e atitudes;

b) Saber dos programas, livros didáticos, exercícios, tecnologias e outros recursos, provenientes das "ferramentas" que o professor utiliza - revelados ao demonstrar que conhece os grandes princípios da educação e do sistema de ensino, seu valor e sua utilidade. Esse conhecimento tem um caráter fundamentalmente técnico, orientado pelo conhecimento do conteúdo, e orienta ao mesmo tempo em que é alimentado por ele;

c) Saber técnico e disciplinar, proveniente da formação acadêmica, revelado pelo professor quando indica conhecer a matéria, o planejamento das aulas e sua organização. Esse conhecimento didático e pedagógico do professor é também pragmático; está intimamente ligado ao contexto de ação, à pessoa do professor e à profissão docente.

Essa interpretação dos saberes docentes buscou associar a questão da natureza e da diversidade dos saberes do professor à de suas fontes, ou seja, de sua proveniência social. Essa abordagem mostrou-se válida para evidenciar os conhecimentos práticos do professor da área contábil. Esse modelo teórico utilizou critérios epistemológicos que se mostraram válidos para captar o conhecimento do professor.

Diante dos saberes identificados na prática pedagógica do professor, no contexto de sua profissão docente, conclui-se que o professor utiliza conhecimentos pessoais e um saber-fazer personalizado, trabalha com os programas e livros didáticos, baseia-se em saberes escolares relativos aos conteúdos ministrados, fia-se em sua própria experiência e retém elementos de sua formação profissional para validá-la.

Além desse quadro de referência sobre os saberes do professor relacionados ao conhecimento de custos, pode-se dizer que os diversos conhecimentos por ele utilizados não são produzidos diretamente por ele; vários desses são, de certo modo, "exteriores" ao ofício de ensinar, pois provêm de lugares sociais anteriores à carreira propriamente dita ou fora da prática docente, como, por exemplo, de sua família, da escola que o formou e de sua cultura pessoal. Outros advêm das universidades, outros são decorrentes da instituição ou do estabelecimento de ensino (programas, regras, princípios pedagógicos, objetivos, finalidades etc.) e outros, ainda, dos pares, dos cursos de aperfeiçoamento etc.

Em síntese, os saberes que servem de base para o ensino, tal como são vistos pelo professor, não se limitam a conteúdos fixos e imutáveis e nem dependem de um conhecimento especializado, pois abarcam diferentes objetos, questões, problemas e conflitos que estão todos relacionados com seu fazer cotidiano.

\section{REFERÊNCIAS}

ARAUJO, A. M. P.; SANTANA, A. L. A.; CARNEIRO, C. M. B. Saberes necessários a prática da educação problematizadora: a pedagogia da autonomia de Paulo Freire no curso de ciências contábeis. In: IAAR-ANPCONT 3rd Internacional Accounting Congress, 2009, São Paulo. Anais eletrônicos... São Paulo: Accounting Internationalization, 2009. 1 CD-ROM. 
BLOCHER, E. J.; CHEN, K. H.; COKINS, G.; LIN, T. W. Gestão estratégica de custos. São Paulo: McGraw-Hill, 2007.

BOURDIEU, P. Esboço de uma teoria da prática. In: ORTIZ, R. (Org.) Pierre Bordieu: sociologia. São Paulo: Editora Ática, 1983.

BORGES, C. M. F. Formação e prática pedagógica do professor de educação física: a construção do saber docente. Belo Horizonte, 1995. Dissertação (Mestrado) - Faculdade de Educação/UFMG, 1995.

BRASIL. Lei n. 9.394/96 de 20 de dezembro de 1996: Lei de Diretrizes e Bases da Educação Nacional. Diário Oficial da República Federativa do Brasil, Brasília, DF, no. 248, dez. 1996, p. 27.833-27.841.

BRASIL. CONSELHO NACIONAL DE EDUCAÇÃO. CÂMARA DE EDUCAÇÃO SUPERIOR. RESOLUÇÃO CNE/CES 10, de 16 de dezembro de 2004. Institui as Diretrizes Curriculares Nacionais para o Curso de Graduação em Ciências Contábeis, bacharelado, e dá outras providências.

CALDEIRA, M. S. A. A apropriação e a construção do saber docente e a prática cotidiana. Cadernos de Pesquisa, n. 95, São Paulo, nov. 1995, p. 5-12.

CUNHA. M. I. Paradigmas científicos e propostas curriculares. Revista Interface Comunicação em saúde: Educ. 2, 1998.

CUNHA, M. I. Ensino como mediação da formação do professor universitário. In: MOROSINI, M. (Org.). Professor do ensino superior: identidade, docência e formação. 2. ed. Brasília : Plano, 2001.

DIÁRIO OFICIAL DA UNIÃO. Cursos avaliados em 2011 com CPC 1 e 2. DOU de 08 de janeiro de 2013, Seção 1, n. 5, p. 7 . Disponível em <http://www.in.gov.br/visualiza/index.jsp?data=08/01/2013\&jornal=1\&pagina=7\&totalArqui vos $=56>$. Acesso em 14/2/2013.

ELBAZ, F. Teaching thinking: a study of practical knowledge. London: Croom Helm, 1983.

FAZENDA, I. C. A. Interdisciplinaridade: um projeto em parceria. 5. ed. São Paulo: Loyola, 2002.

FREIRE, P. Pedagogia da autonomia: saberes necessários à prática educativa. Rio de Janeiro: Paz e Terra, 1996.

Pesquisa sobre a formação de professores - o conhecimento sobre aprender a ensinar. Revista Brasileira de Educação, São Paulo, n. 9, Jun. 1998.

GUARNIERI, M. R. Tornando-se professor: o início na carreira docente e a consolidação da profissão. 1997. 149f. Tese (Doutorado em Educação) - Universidade Federal de São Carlos UFSCar, São Carlos - SP, 1997.

GUERREIRO, R. Gestão do lucro. São Paulo: Atlas, 2006. 
HANSEN, D. R.; MOWEN, M. M. Gestão de custos. São Paulo: Pioneira Thomson Learning, 2003.

HARGREAVES, A. Professorado, cultura y postmodernidad: cambian los tempos, cambia el professorado. Madrid: Morata, 1996.

KNOWLES, J. G.; COLE, A. L.; PRESSWOOD, C.S. Through preservive teacher's eyes: exploring field experiences through narrative and inquiry. NY: Macmillan College Publish Company, 1994.

KOURGANOFF, W. A face oculta da universidade. São Paulo: UNESP, 1990.

LAFFIN, M. O professor de contabilidade no contexto de novas exigências. Contabilidade Vista \& Revista, Belo Horizonte, v. 12, n. 1, p. 57-78, abr. 2001.

MARCONI, M. A.; LAKATOS, E. M. Técnicas de pesquisa. 7. ed. São Paulo: Atlas, 2008.

MASETTO, M. T. Competência pedagógica do professor universitário. São Paulo: Summus, 2003.

MICHELAT, G. Sobre a utilização da entrevista não diretiva em sociologia, críticas metodológicas, investigação social e enquete operária. São Paulo: Polis, 1982.

MINAYO, M. C. O desafio do conhecimento: pesquisa qualitativa em saúde. 11. ed. São Paulo: HUCITEC, 2008.

MIZUKAMI, M. G. M. Ensino: abordagens do processo. São Paulo: EPU, 1986.

MORAES, M. C. O paradigma educacional emergente: implicações na formação do professor e nas práticas pedagógicas. Em Aberto, Brasília, ano 16. n.70, abr./jun. 1996.

MOREIRA. H.; CALEFFE, L. G. Metodologia da pesquisa para o professor pesquisador. Rio de Janeiro: DP\&A, 2009.

MORIN, E. Educação e complexidade: os sete saberes e outros ensaios. São Paulo: Cortez, 2005.

NASSIF, L. A alta reprovação no exame da OAB. Publicado em 16/01/2013. Disponível em <http://www.advivo.com.br/blog/luisnassif/a-alta-reprovacao-no-exame-da-oab>. Acesso em 14/02/2013.

NOSSA, V. Formação do corpo docente dos cursos de graduação em contabilidade no Brasil: uma análise crítica. Contabilidade e Finanças, São Paulo, n. 21, mai-ago. 1999.

NÓVOA, A. (Coord.). Os professores e sua formação. Lisboa, Dom Quixote, 1992.

PERRENOUD, P. Práticas pedagógicas e profissão docente: perspectivas sociológicas. 2. ed. Dom Quixote: Lisboa, 1996. 
Construir as competências desde a escola. Porto Alegre: Artmed, 1999.

PIMENTA, S. G. (org.). Saberes pedagógicos e atividade docente. 2 ed. São Paulo: Cortez, 1999.

Professor reflexivo: construindo uma crítica. In: PIMENTA, S.G. \& GHEDIN, E. (Orgs.). O professor reflexivo no Brasil. Gênese e crítica de um conceito. São Paulo: Cortez, 2002.

; ANASTASIOU, L. G. C. Docência no ensino superior. São Paulo: Cortez, 2002 (Coleção Docência em Formação).

PIMENTEL, M. G. O professor em construção. Campinas, SP: Papirus, 1993.

PORTAL G.1. Exame do Cremesp reprova 54,5\% dos formandos em medicina. Publicação de 06/12/2012. Disponível em: <http://g1.globo.com/educacao/noticia/2012/12/exame-docremesp-reprova-545-dos-formandos-em-medicina.html>. Acesso em 14/2/2013.

SACRISTÁN, J. G. Consciência e ação sobre a prática como libertação profissional dos professores. In: NÓVOA, A. (Org.). Profissão professor. Porto: Porto Editora, 1995.

SANTANA, A. L. A. O perfil do professor de ciências contábeis e seu reflexo no Exame Nacional de Desempenho dos Estudantes - um estudo nas universidades federais do Brasil. 2009. 177f. Dissertação (mestrado) - FEA/USP - Controladoria e Contabilidade, São Paulo, 2009. Disponível em: <http://www.teses.usp.br/teses/disponiveis/96/96133/tde-05052010142132/pt-br.php>. Acesso em: 6 mar. 2011.

SANTOS, B. A gramática do tempo: para uma nova cultura política. São Paulo: Cortez, 2006.

SAVIANI, Demerval. Histórias das idéias pedagógicas no Brasil. Campinas: Autores Associados, 2007.

SCHON, A. D. Educating the reflective practitioner: toward a new designer for teaching and learning in the professions. San Francisco: Jossey - Bass Publ., 1987.

SELLTIZ, C. et. Al. Métodos de pesquisa nas relações sociais. São Paulo: Herder: Edusp, 1965.

SHULMAN, L. S. The wisdom of practice: essays on teaching and learning to teach. San Francisco, Jossey-Bass, 2004.

SLOMSKI, V. G. Saberes e competências do professor universitário: contribuições para o estudo da Prática Pedagógica do Professor de Ciências Contábeis do Brasil. Revista de Contabilidade e Organizações, v. 1, p. 86-106, 2007.

- O conceito de professor investigador: os saberes e as competências necessárias à docência reflexiva na área contábil no Brasil. Revista Universo Contábil, v. 4, n. 4, p. 06-21, 2008a. 
Saberes que fundamentam a prática pedagógica do professor de Ciências Contábeis. In: Congresso USP de Controladoria e Contabilidade, 8., 2008, São Paulo. Anais eletrônicos... São Paulo: 2008b. 1 CD-ROM.

; SLOMSKI, V. Saberes e competências do professor de Ciências Contábeis do Brasil. In: LOPES, J. ; RIBEIRO FILHO, J. F.; PEDERNEIRAS, M.. (Org.). Educação contábil: tópicos de ensino e pesquisa. São Paulo: Atlas, v. 1, p. 135-156. 2008.

et al. Saberes que fundamentam a prática pedagógica do professor de Ciências Contábeis de instituições de ensino superior brasileiras. Revista Brasileira de Contabilidade. v. 178, p. 119-139, 2009.

TARDIF, M. Saberes profissionais dos professores e conhecimentos universitários. Quebec, CRIFPE, 1999.

; LESSARD, C.; LAHAYE, L. Os professores face ao saber: esboço de uma problemática do saber docente. Teoria e Educação, n. 4. Porto alegre, 1991.

; RAYMOND, D. Saberes, tempo e aprendizagem do trabalho no magistério. Educação e Sociedade, Ano XXI, n. 73, dez. 2000.

VALOR ECONÔMICO. Menos da metade dos contadores são aprovados em exame de suficiência. Edição de 21 de setembro de 2012. Disponível em <http://www.valor.com.br/carreira/2839130/menos-da-metade-dos-contadores-saoaprovados-em-exame-de-suficiencia>. Acesso em 14/2/2013.

VASCONCELOS, M. L. M. C. Contribuindo para a formação de professores universitários: relatos de experiências. In: MASETTO, M. (org.). Docência na universidade. Campinas, SP: Papirus, 1998, pp. 77-94.

ZABALZA, M. A. O ensino universitário: seu cenário e seus protagonistas. Porto Alegre: Artmed, 2004. 